\title{
Hepatopancreatic Microsporidiasis (HPM) in Shrimp Culture: A Review
}

\author{
Suresh Kmmari ${ }^{*}$, Srinu Rathlavath ${ }^{2}$, Devika Pillai ${ }^{3}$ and Gadasu Rajesh ${ }^{4}$ \\ ${ }^{1}$ Department of Aquatic Animal Health Management, College of Fishery Science, P.V. \\ Narsimha Rao Telangana Veterinary University, Pebbair, Telangana, India \\ ${ }^{2}$ Departmemt of Fish processing Technology, College of Fishery Science, P.V. Narsimha Rao \\ Telangana Veterinary University, Pebbair, Telangana, India \\ ${ }^{3}$ Department of Aquatic Animal Health Management, Kerala University of Fisheries and \\ Ocean Studies, Panangad, Kerala, India \\ ${ }^{4}$ Department of Fisheries, Andhra Pradesh, India \\ *Corresponding author
}

\section{A B S T R A C T}

\begin{tabular}{|l|}
\hline K e y w o r d s \\
$\begin{array}{l}\text { Enterocytozoon } \\
\text { hepatopenaei, } \\
\text { Prevalence, } \\
\text { Histopathology, } \\
\text { Transmission }\end{array}$ \\
\hline Article Info \\
\hline $\begin{array}{l}\text { Accepted: } \\
\text { 26 December } 2017 \\
\text { Available Online: } \\
\text { 10 January } 2018\end{array}$ \\
\hline
\end{tabular}

Shrimp culture is the most lucrative food production sector in the world and it is having good commodity in international market. This review discusses about the microsporidians especially EHP their distribution, development, transmission, pathogenicity, diagnosis, treatment and prevention methods. EHP causes growth retardation in shrimp causing huge economic losses to shrimp culture. A prevalence of about $79.5 \%$ to $18.51 \%$ has been reported in many countries, majority from Southeast Asian countries. Till now there is no valid treatment available for shrimp farmers because EHP produces spores which are highly resistant and stable for long time in soil and water. It's very difficult to eradicate once spores were in shrimp pond.so we concluded SPF brood stocks, strict pathogens quarantine and Standard management strategies could be the main approach to prevent entry of unwanted pathogens especially EHP.

\section{Introduction}

Aquaculture is the most promising food production sector, providing protein rich supplement for humans and animals worldwide. World aquaculture production continued to grow in 2013, reaching 97.2 million tons with an estimated value of 157 billion US\$. The production of farmed food fish (finfish, crustaceans, molluscs and other aquatic animals) was 70.2 million tons in 2013 , annual growth rate up by $5.6 \%$ from 66.5 million tons in 2012 (FAO, 2016). Shrimp is considered as one of the most traded food item and it commands $15 \%$ of the traded fishery products (Granjoor, 2015). Total shrimp production in the world is dominated by two penaeid species (Penaeus vannamei and Penaeus monodon) which contributes around $80 \%$ of total shrimp production (FAO, 2009). The dominance of $P$. vannamei over $P$. 
monodonis due to its fast growth rate, low protein requirement and Availability of SPF, SPR brood stock in the worldwide.

Modernization culture techniques, high stocking densities and use of compound pelleted feeds in order to achieve higher production creates an imbalance in aquatic environment leading to diseases (Alavandi et al., 1995). Diseases have had a major impact on shrimp culture and considered as one of the most serious constraints affecting production. Diseases in shrimps are caused by different agents like viruses, bacteria, parasites, fungi, nutritional deficiencies and changes in environmental parameters. Most of the microbes of shrimps are a part of natural environment of marine, brackish and fresh water system and these may become pathogenic and cause diseases in shrimp culture under stress conditions. The conditions leading to diseases in fish depends on the availability of pathogen, the quality of environment and the health status of fish. The balance of these conditions ensures the health of the fish (Inglis, 1993).

In shrimp farming the most common shrimp diseases (mostly by virus and bacteria) has been studied, and routinely observed. These pathogenic microbes can cause a significant production losses in penaeid shrimp culture i.e. White Spot Syndrome Virus (WSSV) that cause white spot disease; Yellow Head Disease (YHD) caused by yellow head virus; Covert Mortality Disease (CMD) caused by covert mortality nodavirus; Macrobranchium rosenbergii nodavirus cause White Tail Disease (WTD) (Thitamadee et al., 2016). Infectious bacterial pathogens emerged in shrimp culture and act as threat to shrimp cultivation. Species from Vibrio casually cause the infection to shrimp culture called acute hepatopancreatic necrosis disease (AHPND) by Vibrio parahaemolyticus (Tran et al., 2016).Recently the shrimp farms in the
Southeast Asia have been affected by the microsporidian parasite, Enterocytozoon hepatopenaei (EHP) in P. vannamei culture.

The parasite was first reported from Penaeus monodon in Thailand (Chayaburakul et al., 2004), later in 2009, this was isolated from $P$. monodon in Thailand was described and named as Enterocytozoon hepatopenaei (EHP) (Tourtip et al., 2009). Though EHP is not associated with mortality of shrimps, it will cause growth retardation in $P$. vannamei and P. monodon (Newman, 2015). This parasite is also been reported from China, Indonesia, Malaysia, and Vietnam. In India EHP was first reported by Rajendran et al., (2016). The economic loss in shrimp production due to EHP appears to be significant.

\section{Microsporidia}

Microsporidia constitute a group of sporeforming unicellular eukaryotic parasites that are ubiquitous. They were once considered protozoans or protists (Adl et al., 2012), but are now known to be more closely related to fungi, or a sister group to fungi by genomic taxonomy (Newman, 2015). In general, Microsporidia are responsible for common diseases of crustaceans and fish, and most of them are opportunistic parasites. Microsporidia have been known to science for about 150years, and 1300 to 1500 species in 187 genera have been described. These unique organisms are strictly intracellular parasites with relatively uniformlife cycle (Cali and Takvorian, 1999).

Microsporidia lack motile structures, such as flagella, and produce highly resistant spores capable of surviving outside their host for up to several years. Spore morphology is useful in distinguishing between different species. Spores of EHP appeared oval in shape measuring 1.7-1.0 $\mu \mathrm{m}$ (Rajendran et al., 2016) Approximately 43 microsporidian genera from 
crustaceans have been described and 11 of these have been reported from shrimps including Agmasoma, Ameson, Enterocytozoon, Inodosporus, Myospora, Perezia, Pleistophora, Thelohania, Tuzetia, Vairimorpha and Vavraia. Microsporidia have been reported from about 20 species of marine or estuarine shrimps and eight species of fresh water crayfish.

\section{Hepatopancreatic microsporidiasis (HPM)}

Shrimp farms in Southeast Asia have been increasingly reporting the occurrence of severely retarded growth among shrimp populations, and shrimp from affected ponds were found to be heavily infected with the microsporidian, Enterocytozoon hepatopenaei (EHP) (Tourtip et al., 2009; Sritunyalucksana et al., 2014). It is a parasite of penaeid shrimp, EHP infections have been found in both black tiger prawns $P$. monodon and Pacific white shrimp $P$. vannamei. EHP is Obligatory, spore forming parasite, known to infect hepatopancreatic epithelial cell by changing their biochemical parameters such as as total protein, albumin, aspartate transaminase (AST), alanine transaminase (ALT) and alkaline phosphatase were measured in the haemolymph of naturally and experimentally EHP-infected shrimp (Santhoshkumar et al., 2016). Aspartate transaminase (AST), alanine transaminase (ALT) and alkaline phosphatase are considered generally indicated the tissue damage (Pan et al., 2003ab), and these parameters would help to understand the functional status of hepatopancreas in EHP infected shrimp.

\section{Distribution and transmission}

Microsporidians are ubiquitous parasites, has been reported from different countries (Table 1). The microsporidian parasite, EHP was described as an obligatory intracellular parasite, replicates within the cytoplasm of the tubular epithelial cells of the hepatopancreas and reported to be transmitted horizontally by cannibalism, only in shrimp (Chiyansuvata $e t$ al., 2015). Microsporidian life histories vary in response to selective pressures for replication and opportunities for transmission. Although horizontal transmission is the main transmission via water (Salachan et al., 2017) route among the aquatic microsporidia, many species utilize both horizontal and vertical transmission (Dunn et al., 2001; Smith, 2009). The usage of live feeds possesses significant threat to shrimp culture. The infected live feeds can infect and spread EHP through faeces (Newman, 2015) and EHP can be directly transmitted to other shrimps via water (Salachan et al., 2017). Along with water and feed, Artemia and Grapsidae family crabs are also recognised as the potential carriers of EHP Chiyansuvata et al., (2015).

\section{Infestation}

The disease caused by Enterocytozoon hepatopenaei (EHP) is referred as hepatopancreatic microsporidiosisis (HPM), since the parasite is confined to the shrimp hepatopancreas (CIBA, 2016). Microsporidians have been shown to infect only the tubule epithelial cells of the crustacean hepatopancreas (Anderson et al., 1989; Hudson et al., 2001). This parasite will take about 14 days to commence infection (Salachan et al., 2017).

\section{Clinical signs}

The clinical signs of EHP infection are not specific and associated with growth retardation (Fig. 1), White Faeces Syndrome (WFS)and size variation are the major clinical signs of EHP (Rajendran et al., 2016: Salachan et al., 2017). It infects only the tubules of the hepatopancreas in shrimp, and damages the ability of this critical organ to get nutrition from feed. It is widely understood 
that EHP does not cause mortality but heavily limits growth of the shrimp. Severe infections by EHP can alters the susceptibility to other bacterial infections like Vibrio spp. in shrimp farms leads to mortalities.

\section{Pathological changes}

Histologically, severe necrotic changes can be seen in the shrimp hepatopancreas. The common pathological changes associated with Enterocytozoon hepatopenaei is seen in hepatopancreas of shrimp (Fig. 2). Large eosinophilic to basophilic inclusions indicating the presumptive developmental stages of EHP in the tubular epithelium. These changes were predominantly seen in distal end of hepatopancreatic tubules and showing the Detachment of tubular epithelium from basal membrane of hepatopancreas (Fig. 2A). Basal part of the tubular epithelium showed granular material and spore, sloughing of the tubular epithelial cell was pronounced due to heavily infected Hepatopancreas (Fig. 2C) and followed by heavy cellular damage (Fig. 2D).

Table.1 Prevalence of EHP in different countries

\begin{tabular}{|c|c|c|c|}
\hline Country & Year & Prevalence & References \\
\hline Thailand & 2009 & ND & Tourtip et al., 2009 \\
\hline Thailand & 2013 & ND & Suebsing et al., 2013 \\
\hline Thailand & 2013 & ND & Tangprasittipap et al., 2013 \\
\hline Vietnam & 2015 & ND & Tang et al., 2015 \\
\hline India & 2016 & With WFS (96.4\%) Without WFS (39.7\%) & Rajendran et al., 2016 \\
\hline India & 2016 & $69 \%$ & Biju et al., 2016 \\
\hline UK & 2009 & ND & Tourtip et al., 2009 \\
\hline USA & 2015 & ND & Tang et al., 2015 \\
\hline India & 2017 & $18.51 \%$ & Giridharan and Uma., 2017 \\
\hline China & 2017 & $\begin{array}{l}\text { Greenhouse ponds }(54.4 \%) \text {, Earthen ponds } \\
(79.5 \%)\end{array}$ & Chen et al., 2017 \\
\hline
\end{tabular}

Fig.1 A. Showing the size variation in same aged shrimps in EHP infected pond. B. White faeces floating on water surface

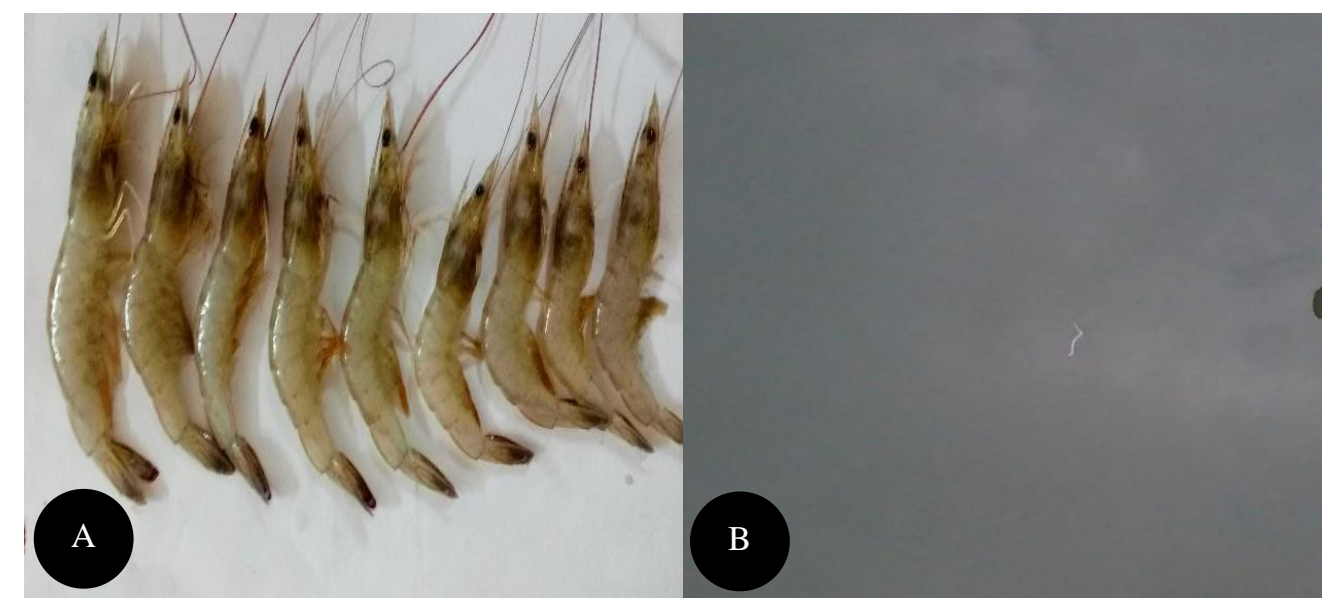


Fig.2 Histological changes of shrimp infection with EHP

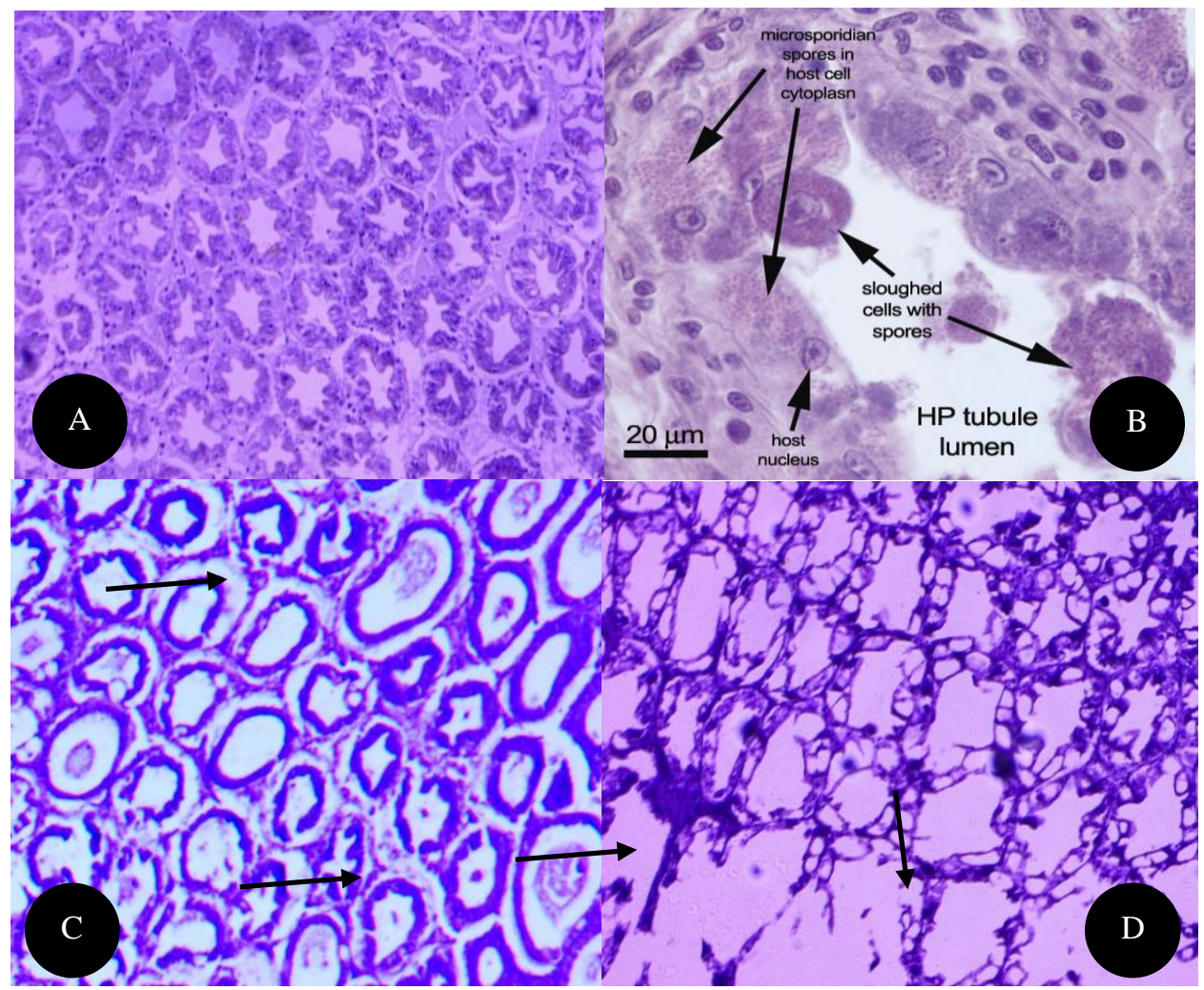

$P$. vannamei infection with EHP. A. Normal structure of hepatopancreas, B. Spores and sloughing of hepatopancreas, C. Detachment of tubules of hepatopancreas, D. Heavy cellular damage.

Fig.3 Flow chart of EHP diagnosis

EHP Diagnosis

\begin{tabular}{ll} 
DNA Based & \multicolumn{1}{c}{ Microscopic Based } \\
1. Polymerase chain reaction & 1. Hematoxylin and eosin \\
& 2. In Situ hybridization \\
& 3. Scanning Electron Microscopy \\
4. Transmission Electron Microscopy
\end{tabular}




\section{Prevalence}

There is a close connection with EHP and white faeces syndrome in shrimp culture. Without WFS (39.7\%) and With WFS (96.4\%) of prevalence was identified in EHP infected ponds (Rajendran et al., 2016). Nevertheless the prevalence of EHP depends on the conditions of culture pond and the prevalence of EHP in Greenhouse ponds (54.4\%) was lower than that of in earthen ponds (79.5\%) (Shen et al., 2017).

\section{Diagnosis}

EHP can be diagnosed mainly by two methods (Fig. 3) i.e. DNA based (PCR and LAMP) and Microscopic based (Hematoxylin-eosin, In Situ hybridization, Scanning Electron Microscopy and Transmission Electron Microscopy) (Karhikeyan et al., 2016). All these methods can be performed by careful observation of spores in faecal samples and hepatopancreatic tissue by microscopic examination of wet smears and histology. Further, EHP can be demonstrated with techniques like PCR and LAMP are used for rapid diagnosis in shrimp farms and hatcheries. Live feeds, PL and brood stock can be tested before rearing into culture ponds to keep EHP at bay.

\section{Treatment}

Known treatment is not available till to date for EHP. But some of shrimp farmers employing their own methods to keep the parasite away. We have found discussions through the local farmers or producers in Andhra Pradesh, India, by applying garlic and bitter guard paste (30-40 g/ $\mathrm{kg}$ of feed).

In Indonesia, local producers applying Probiotics, Garlic paste (10-20g/kg feed) and vitamin C ( $2 \mathrm{~g} / \mathrm{kg}$ feed) to avoid EHP and WFS in shrimp culture (Tang et al., 2016)

\section{Prevention and control}

Good management practices and biosecurity measures in cultured farms are only way to keep pathogen away. Moreover, once spores are present in ponds it is difficult to eradicate the disease. Hence it is recommended to follow strict biosecurity and good pond management protocols like drying, ploughing, chlorination and de-chlorination of water and liming can be done to prevent EHP infection through water and aquatic carriers. EHP tested seed can be stocked to ensure absence of EHP (CIBA, 2016). Avoid live animals like polychaetes for feeding brood stock. If this advice is ignored, such feeds should have to be frozen and Pasteurized (heating at $70^{\circ} \mathrm{C}$ for 10 minutes) before it to use since it would kill AHPND, Bacteria, Viruses and EHP (Sritunyalucksana et al., 2014). Shen et al., 2017 stated that construction of greenhouse ponds could in a certain extent control spread of pathogens by the avoiding the entry of carriers in cultured ponds and concluded that use of SPF brood stocks, strict pathogens quarantine and Standard management strategies could be the main approach to prevent entry of unwanted pathogens.

The current review is addresses about microsporidian parasite, EHP and its effects on shrimp culture. EHP is an emerging disease in shrimp culture causing significant production losses to farmers. Diseases have had a great impact on shrimp culture and the durability of the production is dependent on the equilibrium between (i) The environment (ii) The prevention of diseases by diagnosis and epidemiological surveys of the pathogens, and (iii) The health condition of the shrimp. Shrimp culture is also dependent on the selection of animals resistant to diseases. Therefore, the prevention and the control of shrimp diseases need an integrated approach in which knowledge of shrimp immunity must be improved, consideration given to other 
research areas related to pathology and shrimp physiology and in close connection to research in genetics. It is essential to focus efforts on producing high quality seed, follow improved better management practices, routine farm biosecurity measures and responsible trade practices to prevent epizootics in aquaculture. The establishment of regular health checks would permit the detection of shrimp immune deficiencies and consequently, reduce disease vulnerability, but at the same time, it could also contribute to the control and improvement of environment quality.

\section{References}

Adl, S.M., Simpson, A. G., Lane, C. E., Lukeš, J., Bass, D., Bowser, S. E., Brown, M., Burki, F., Dunthorn, M., Hampl, V., Heiss, A., Hoppenrath, M., Lara, E., leGall, L., Lynn, D. H., McManus, H., Mitchell, E. A. D., Mozley-Standridge, S. E., Wegener Parfrey, L., Pawlowski, J., Rueckert, S., Shadwick, L., Schoch, C., Smirnov, A. and Spiegel, F. W. 2012. The revised classification of eukaryotes. Journal of Eukaryot. Microbiol. 59: 429-493.

Alavandi, S.V., Vijayan K.K., and Rajendran K.V. 1995. Shrimp diseases, their prevention and control. CIBA Bulltin. 3: 117.

Anderson, I.G., Shariff, M. and Nash, G. 1989. A hepatopancreatic microsporidian in pond rearedtiger shrimp, Penaeus monodon, from Malaysia. Journal of Invertebrate Pathology, 53:278-28.

Cali, A. and Takvorian, P.M. 1999. Developmental morphology and life cycle of microsporidia. In: Wittner, M., Weiss, L.M (Eds.), the microsporidia and microsporidiosis, ASM Press, Washington, D.C., pp. 85-128.

Chayaburakul, K., Nash, G., Pratanpipat, P., Sriurairatana, S. and Withyachumnarnkul, B. 2004. Multiple pathogens found in growth-retarded black tiger shrimp Penaeus monodon cultivated in Thailand. Dis Aqua Org, 60(2): 89-96.
Chiyansuvata, P., Chantangsi, C., Chutmongkonkul, M., Tangtrongpiros, J. and Chansue, N. 2015. Proceedings of the $14^{\text {th }}$ Chulalongkom University Veterinary Conference, Bangkok, Thailand.

Dunn, A. and Smith, J.E. 2001. Microsporidian life cycles and diversity: the relationship between virulence and transmission. Microbe. Infect, 3:381-388.

FAO (Food and Agriculture Organization of the United Nations), 2009. Fishmeal market report-May 2009. Food and Agriculture Organization of the United NationsGlobefish. Online: http://www.globefish.org

FAO, 2016. Global aquaculture production statistics: an overview, Rome. FAO. pp. 68.

Ganjoor, M. 2015. A Short Review on Infectious Viruses in Cultural Shrimps (Penaeidae Family). Fisheries and Aquaculture Journal, 2015.

Giridharan, M and Uma, A. 2017. A Report on the Hepatopancreatic Microsporidiosis Caused by Enterocytozoon hepatopenaei (EHP) in Penaeus vannamei (Pacific White Shrimp) Farms in Thiruvallur District, Tamilnadu, India. Int.J.Curr.Microbiol.App.Sci, 6(6): 147-152.

Hudson, D.A., Hudson, N.B. and Pyecroft, S.B. 2001. Mortalities of Penaeus japanicus prawn associated with microsporidian infection. Australian Veterinary Journal, 79: 7.

Inglis, V., Roberts, R.J. and Bromage, N.R. 1993. Bacterial Diseases of Fish. Blackwell Publishing Ltd, Oxford. P. 312.

Karthikeyan, K and Sushakaran, R. 2016. Shrimp microsporidian parasite Enterocytozoon hepatopenaei (EHP): Threat for cultivated penaeid. South Indian Journal of Biological Sciences. 2(4): 388-394.

Newman, S.G. 2015. Microsporidian Impacts shrimp production - industry efforts address control, not eradication. Glob Aquac Advocate.16-17(March/April).

Pan C.H., Chien Y.H. and Hunter B. 2003a. The resistance toammonia stress of Penaeus monodon Fabricius juvenile feddiets supplemented with astaxanthin. Journal of Experimental Marine Biology and Ecology 
297, 107-118.

Pan C.H., Chien Y.H. and Hunter B. 2003b. Alterations of antioxidant capacity and hepatopancreatic enzymes in Penaeus Monodon (Fabricius) juveniles fed diets supplemented with astaxanthin and exposed to Vibriodamsela challenge. Journal of the Fisheries Society of Taiwan.30, 279-290.

Rajendran, K.V., Shivam, S., Ezhil Praveena, P., Sahaya Rajan, J.J., Sathish Kumar, T., Satheesha Avunje., Jagadeesan, V., Prasad Babu, S.V.A.N.V., Ashish Pande., Navaneeth Krishnan, A., Alavandi, S.V. and Vijavan, K.K. 2016. Emergence of Enterocytozoon hepatopenaei (EHP) in farmed Penaeus (Litopenaeus) vannamei in India. Aquaculture. 454: 272-280

Salachan, P.V., Jaroenlak, P., Thitamadee, S., Itsathitphaisam O. and Sritunyalucksana, K., 2017. Laboratory cohabitation challenge model for shrimp hepatopancreatic microsporidiosis (HPM) caused by Enterocytozoon hepatopenaei (EHP). BMC Veterinary Research. 13(9): 1-7.

Santhosh kumar, S., Shivakumar, S., Vimal, S., Abdul Majeed, S., Taju, G., Haribabu, P., Uma, A. and Sahul Hameed, A.S. 2016. Biochemical changes and tissue distribution of Enterocytozoon hepatopenaei (EHP) in naturally and experimentally EHP-infected white leg shrimp, Litopenaeus vannamei (Boone, 1931), in India. Journal of Fish Diseases. 40: 529-539.

Shen, H., Jiang, G., Wan, Xihe, Fan, Xianping, Qiao, Y., Shi, Wenjum, Li, Hui and Wang Labao. 2017. Multiple Pathogens Prevalent in Shrimp Penaeus vannamei Cultured from Greenhouse Ponds in Jiangsu Province of China. J Aquac Res Development. 8(10): 15.

Smith, J.E. 2009. The ecology and evolution of microsporidian parasites. Parasitol, 136: 1901-1914.

Sritunyalucksana, K., Sanguanrut, P., Salachan, P. V., Thitamadee, S. and Flegel, T. W. 2014. Urgent appeal to control spread of the shrimp microsporidian parasite Enterocytozoon hepatopenaei (EHP). $<$ http://www.enaca.org/modules/news/ article.php?article_id=2039>.

Tang, K.F.J., Han, J.E., Aranguren, L.F., WhiteNoble, B., Schmidt, M.M., Piamsomboon, P., Risdiana, E. and Hangogono, B. 2016. Dense populations of the microsporidian Enterocytozoon hepatopenaei (EHP) in feces of Penaeus vannamei exhibiting white faeces syndrome and pathways of their transmission to healthy shrimp. Journal of invertebrate pathology, 140:1-7.

Thitamadee S, Prachumwat A, Srisala J, Jaroenlak P, Salachan PV, Sritunyalucksana K, Flegel TW, and Itsathitphaisarn O. 2016. Review of current disease threats for cultivated penaeid shrimp in Asia. Aquaculture 452, 69-87.

Tourtip, S., Wongtripop, S., Stentiford, G. D., Bateman, K. S., Sriurairatana, S., Chavadej, J. and Withyachumnarnkul, B. 2009. Enterocytozoon hepatopenaei sp. nov. (Microsporida: Enterocytozoonidae), a parasite of the black tiger shrimp Penaeus monodon (Decapoda: Penaeidae): Fine structure and phylogenetic relationships. Journal of invertebrate pathology, 102(1): 21-29.

Tran L, Nunan L, Redman RM, Mohney LL, Pantoja CR, Fitzsimmons K, Lightner DV. 2013. Determination of the infectious nature of the agent of acute hepatopancreatic necrosis syndrome affecting penaeid shrimp. Dis Aquat Org. 105(45), e55.

\section{How to cite this article:}

Suresh Kmmari, Srinu Rathlavath, Devika Pillai and Gadasu Rajesh. 2018. Hepatopancreatic Microsporidiasis (HPM) in Shrimp Culture: A Review. Int.J.Curr.Microbiol.App.Sci. 7(01): 3208-3215. doi: https://doi.org/10.20546/ijcmas.2018.701.383 